Gonzalo MARTÍNEZ CAMINO

Universidad de Cantabria

\title{
CREATIVIDAD Y MARKETING: LA RELACIÓN ENTRE EL ESLOGAN Y EL MENSAJE AUDIOVISUAL EN LOS ANUNCIOS TELEVISIVOS RACIONALES Y EN LOS EMOCIONALES
}

\section{OBJETIVOS}

El objetivo principal de este trabajo es analizar la relación que se da entre la creatividad presente en el texto escrito de los eslóganes (a partir de ahora SLG) que suelen aparecer al final de los anuncios publicitarios televisivos y el resto de su mensaje audiovisual.

Para ver cómo esta relación puede variar entre distintos anuncios, se recurre a la distinción que David Bernstein (1974) y Paul Simpson (2001) hacen entre anuncios racionales (reason ads) y anuncios emocionales (tickle ads): los primeros se caracterizan por la exposición del producto/logo y las razones por las que debe ser comprado, los segundos son más indirectos: insinúan más que dicen. Es decir, el anuncio prototípicamente emocional es aquél que nos hace preguntarnos si eso que estamos viendo es un anuncio. Por lo tanto, tenemos dos polos entre los que se extiende una gradación de posibilidades intermedias; en el extremo racional de la misma, los anuncios comienzan comunicándonos que son anuncios; en el emocional, el televidente inicia su tarea interpretativa preguntándose si esto es un anuncio.

Para alcanzar los objetivos propuestos, el primer paso dado fue grabar 100 anuncios televisivos 1) entre las 20:00 y las 23:00 horas, 2) en los intervalos entre noticieros, partidos de fútbol y películas. Se guardaron estas dos condiciones para dar homogeneidad y representatividad al corpus. Posteriormente se seleccionaron los anuncios que

1) terminaran el mensaje con un SLG escrito

2) y fueran un ejemplo de uno de los dos prototipos ya definidos:

2.1) racional (anuncios prototípicamente racionales, a partir de ahora APR): (2.1.1) deja claro desde un principio que estamos recibiendo un mensaje publicitario, (2.1.2) muy probablemente mediante la aparición del producto, su nombre y/o su logo (2.1.3) sobre el que se predican una serie de características que lo vuelven una mercancía deseable;

2.2) emocional (anuncios prototípicamente racionales, a partir de ahora APE): (2.2.1) el anuncio genera en el televidente una incertidumbre genérica, (2.2.2) pues insinúa más que muestra, predica $y / o$ argumenta, de tal manera que, durante unos segundos, el receptor alberga dudas de si lo que ve es un anuncio.

La mayoría de los anuncios grabados no respondían a ninguno de estos prototipos y fueron descartados. En consecuencia, debemos advertir que, dado el tamaño del corpus el análisis de cualquiera de estos objetivos sólo nos indica tendencias que deben servir como punto de partida para más estudios. 
Una vez hecha la selección de los SLG, se analizó la creatividad en ellos presente y su relación con la parte audiovisual del mensaje. Ahora bien, ¿qué entendemos por creatividad?

\section{LA NOVEDAD}

El presente estudio basa su análisis en el concepto de novedad que Carol J. Hardin (2001) analiza como parte del lenguaje persuasivo de los anuncios televisivos en lengua española. Esta autora toma como punto de partida, a su vez, a Robin Lakoff (1982), quien define la novedad en el marco de la teorías de las implicaturas de Paul Grice (1989). Este autor entiende que, si la comunicación verbal es una conducta racional, debe guiarse de acuerdo con cuatro máximas resumibles en un principio cooperativo:

Make your conversational contribution such as is required, at the stage at which it occurs, by the accepted purpose or direction of the talk exchange in which you are engaged. (Grice $1989: 26$ ).

Maxim of quantity: 1 . Make your contribution as informative as is required (for the current purpose of the exchange). 2. Do not make your contribution more informative than is required.

Maxim of Quality: Try to make your contribution one that is true: 1. Do not say what you believe to be false. 2. Do not say that for which you lack adequate evidence.

Maxim of Relation: Be relevant.

Maxim of Manner: 1. Avoid obscurity of expression. 2. Avoid ambiguity. 3. Be brief. 4. Be orderly

Cuando el publicista realiza un enunciado que incumple bien el principio cooperativo bien alguna de sus máximas, su receptor no piensa que no quiera cooperar sino que busca comunicarle una información que no está codificada en el mensaje: la violación es la señal para que el oyente realice una inferencia. A esta información inferida se la denomina implicatura: «son implicaturas todos los contenidos asociados a oraciones de cuya veracidad depende que el mensaje se haya atenido a las pautas de cooperación habituales que se dan entre los hablantes » (Núñez \& Teso 1996 : 83).

De acuerdo con Lakoff (1982), la novedad se produce en la publicidad cuando se viola la máxima de la manera con el fin de atraer la atención del receptor y grabar el mensaje en su memoria. Esta autora señala 5 categorías de novedad: léxica, morfológica, sintáctica, semántica y pragmática. A estas cinco categorías, Hardin (2001 : 29-31) añade otras tres de su propio magín: explícita, situacional y asociación novedosa. Veamos cómo aparecen definidas estas categorías en la obra de Hardin (los ejemplos pertenecen al corpus de este trabajo):

a) Novedad léxica: neologismos y préstamos de otras lenguas o de jergas especializadas; ejemplo: Auto emoción (Seat).

b) Novedad morfológica: transposiciones sorprendentes, encadenamientos de adjetivos, usos poco habituales de los determinantes; ejemplo: $\boldsymbol{t} \boldsymbol{u}$ otro banco y cada día el de más gente (ING). 
c) Novedad sintáctica: uso de estructuras elípticas; ejemplo: Chocolates Valor. Placer adulto.

d) Novedad semántica: comparaciones elípticas; ejemplo: Puente Aéreo e Iberia Plus. Más para ti (más que qué o que quién).

e) Novedad pragmática: aberraciones discursivas tales como diálogos no usuales; ejemplo: (situación: simulación de una entrevista radiofónica deportiva a pie de campo. La pregunta está elidida y directamente aparece la contestación en voz-en-off de un supuesto futbolista) sí, bueno, es un Hyundai Matrix World Cup, ¿no? Con motor gasolina y diesel common rail, llantas de aleación y aire acondicionado desde sólo 12.922 euros. Ahí está.

f) Novedad explícita: uso de términos léxicos que indiquen novedad; ejemplo: el McMenu Mcnifico, con la nueva hamburguesa Mega. Mucho más grande (McDonalds).

g) Novedad situacional: presentación de situaciones extrañas o desarrollo extraño de situaciones habituales; ejemplo: el anuncio comienza con un joven que camina hacia la cámara. De pronto, se gira y corre. Parece que se estrella contra una pared, pero no, en realidad la atraviesa, y luego otra y otra y otra. Corre y desconocemos su propósito pero una majestuosa música de fondo hace que nos lo imaginemos épico. Al poco, en paralelo, se le une una joven. Cruzando paredes, salen al exterior, pero no se detienen, siguen corriendo por una especie de bosque en medio de la noche. Hasta que cada uno llega a la base de un gran árbol y ascienden por él. La cámara los enfoca desde diversos ángulos mientras se acercan al final del tronco. La música alcanza su clímax y, entonces, una vez que llegan a la punta del árbol, saltan al vacío en dirección a un espacio infinito tiznado de luz de luna que su voluntad y su juventud hacen que parezca abarcable. El anuncio termina con la aparición del SLG: Levi's. Libertad para moverte.

h) Asociaciones novedosas: predicación de cualidades que no son intrínsecas al producto; ejemplo: el chocolate no nos hace gozar como se insinúa el anuncio de Chocolates valor; el mensaje comercial comienza con una «lolita» sacando el chocolate de un cajón donde está guardado y consumiéndolo a solas con gran fruición, en una habitación iluminada por una cálida luz indirecta mientras suena una música muy sugerente y sensual. En ese momento, llegan sus padres y su hermana pequeña. Un primer plano muestra el escándalo de la esta; otra toma nos enseña la reacción de culpabilidad de la degustadora sorprendida.

\section{ANÁLISIS CUANTITATIVO}

En el corpus encontramos 5 APR. Se escriben entre paréntesis las formas de novedad que encontramos en cada SLG:

1) Edesa. Para la gente práctica.

(novedad sintáctica: elipsis; asociación novedosa)

2) Phillipshave. Juntos hacemos tu vida mejor.

(novedad semántica: mejor que qué) 
3) Pescados de crianza. Pescados de confianza.

(novedad sintáctica: elipsis y paralelismo; asociación novedosa)

4) Amena Auna. De profesional a profesional.

(novedad sintáctica: elipsis; asociación novedosa)

5) Braun. Diseñado para marcar la diferencia.

(novedad sintáctica: elipsis; novedad semántica; novedad explícita: la diferencia implica cambio, ¿diferente respecto a qué?)

En cambio, frente a los 5 APR, encontramos 14 APE:

1) Levi's. Libertad para moverte.

(novedad sintáctica: elipsis; asociación novedosa)

2) Vodafone. ¿Cómo estás?

3) La fibra con sabor a Cola-Cao.

(asociación novedosa)

4) As. Cambiate a As.

5) Puente Aéreo e Iberia Plus. Más para ti.

(novedad sintáctica: elipsis; novedad semántica: más que quién o que qué)

6) Sandoz. Since 1870.

(novedad sintáctica: elipsis; novedad léxica: utilización de palabras de otro idioma)

7) Nuevo Alfa 156. La evolución de la tecnología.

(novedad sintáctica: elipsis; novedad explícita: implícita en la palabra evolución; asociación novedosa)

8) Red Bull te da aalas.

(asociación novedosa)

9) Cepsa. Toda tu energía.

(novedad morfológica: uso polisémico de los posesivos; novedad sintáctica: elipsis)

10) Hugo. Your fragance, your rules.

(novedad léxica: utilización de palabras de otro idioma; novedad sintáctica: elipsis)

11) Salta. ¿Qué te apetece?

12) Castilla y León. Cambia tus vacaciones. (asociación novedosa)

13) Damm. Cerveceros desde 1876. (novedad sintáctica: elipsis)

14) Miracle. Tú lo haces posible.

(novedad pragmática: indeterminación estratégica en el uso de los deícticos tú y lo y en el verbo hacer; asociación novedosa)

Lo obvio es la predominancia de la estrategia emocional (14\% del corpus) frente a la racional (5\%). Semejante desproporción se compensa si, al grupo de APR, le añadimos estos otros 3 SLG:

1) Corega. Fijación y limpieza perfectas.

(novedad sintáctica: elipsis)

2) Signal Integral. El cuidado más completo de Signal.

(novedad sintáctica: elipsis)

3) Dove. Sentirás la diferencia. 
(novedad sintáctica: elipsis; novedad semántica y novedad explícita: en ambos casos, ímplita en la palabra diferencia)

¿Por qué no los hemos incluido desde un principio entre los APR? Porque no encajan exactamente con el prototipo. Mientras que en los APR primero se presenta la marca que se vende y luego se dan las propiedades por las que hay que comprarla, en estos tres anuncios se hace justo al revés. De esta forma, nos encontramos con que se hace una exposición de las razones para comprar el producto (estrategia racional), pero, al no comenzar el mensaje presentándonos el producto, nos falta un marco genérico o guión cognitivo en el que interpretar la exposición de las ventajas del producto, así que, durante unos segundos, no sabemos muy bien de qué va esta exposición; surge cierta incertidumbre genérica (estrategia emocional): ¿estoy viendo un anuncio de televisión? En cualquier caso, incluso si les damos por APR, nos encontramos con que un total de 8 anuncios supera escasamente el $50 \%$ de los APE.

Una vez que tenemos estos corpora de SLG, el siguiente paso es comprobar qué elementos de novedad crearon los publicistas cuando los escribieron. Hay que aclarar que, de los 8 categorías, la de novedad situacional, obviamente, no es aplicable a los SLG. Dicho esto, los resultados son los siguientes: 1) APR:

1.1) novedad léxica: 0

1.2) novedad morfológica: 0

1.3) novedad sintáctica: 4 elipsis y 1 paralelismo

1.4) novedad semántica: 2

1.5) novedad pragmática: 0

1.6) novedad explícita: 1

1.7) asociaciones novedosas: 3

2) Anuncios casi prototípicamente racionales (a partir de ahora cuasi-racionales):

2.1) novedad léxica: 0

2.2) novedad morfológica: 0

2.3) novedad sintáctica: 3 elipsis

2.4) novedad semántica: 1

2.5) novedad pragmática: 0

2.6) novedad explícita: 1

2.7) asociaciones novedosas: 0

3) APE:

3.1) novedad léxica: 2 utilizaciones de extranjerismos

3.2) novedad morfológica: 1

3.3) novedad sintáctica: 7 elipsis

3.4) novedad semántica: 1

3.5) novedad pragmática: 1

3.6) novedad explícita: 1

3.7) asociaciones novedosas: 6

\section{COMENTARIO DE ESTOS RESUlTAdOS}

Parece claro que los publicistas prefieren no crear novedades en los SLG, excepto cuando hablamos de la construcción de asociaciones y, sobre todo, de las 
elipsis sintácticas (a partir de ahora ES). Además, ambos hechos prevalecen por encima de la distinción entre racionales y emocionales.

Sin embargo, sobre este fondo, parecen sobresalir dos datos diferenciales. La frecuencia de las ES es mucho más alta en los SLG de los APR que en los de los APE: un $80 \%(4 / 5)$ frente a un 50\% (7/14). Si a los 5 APR sumamos los 3 cuasiracionales, la tendencia adquiere un perfil más claro, pues, si calculamos el porcentaje sobre 8 en lugar de sobre 5 , tenemos que los publicistas crean estas ES en el 87 '5\% de los SLG de anuncios racionales.

En cuanto a la asociación novedosa, ésta suele acompañar a los APR que presentan ES. En cambio, no lo hace en el caso de los cuasi-racionales. Quizá sea éste el mayor punto de divergencia que este análisis encuentra entre los SLG de un grupo y los del otro. Por otro lado, se encuentra la asociación novedosa en 6 de los SLG de los 14 APE, es decir, en el 42,85\%. De estos seis casos, en 4 se ve acompañada de la ES. Esto supone que, sobre un total de 14 anuncios, esta combinación de novedades se da en el $28,57 \%$ de los especímenes. Si calculamos el porcentaje de anuncios que, presentando asociación novedosa, también presentan ES (4/6), obtenemos un resultado del 66,66\%.

\begin{tabular}{|c|c|c|c|}
\hline & \multicolumn{3}{|c|}{ Total del corpus: 100anuncios } \\
\hline clases de anuncios & APR & $\begin{array}{c}\text { cuasi- } \\
\text { racionales }\end{array}$ & APE \\
\hline extensión de la clase en el corpus & 5 & 3 & 14 \\
\hline ES & $4(80 \%)^{*}$ & $3(100 \%)$ & $7(50 \%)$ \\
\hline asociación novedosa & $3(60 \%)$ & $0(0 \%)$ & $6(42,85 \%)$ \\
\hline ES y asociación novedosa & $4(80 \%)$ & $0(0 \%)$ & $4(28,57 \%)$ \\
\hline
\end{tabular}

* Estos porcentajes se calculan sobre el total de la clase, no del corpus

Así las cosas, podemos concluir que la creación, en el SLG, de una ES es una característica casi genérica de los APR y una variedad abundante pero no preponderante en los de los APE. También se puede afirmar que tanto en los APR como en los APE es probable, aunque no necesario, que las ES aparezcan acompañadas de una asociación novedosa; por el contrario, esta relación no se da en los cuasi-racionales

\section{NOVEDAD, CREATIVIDAD Y ELIPSIS SINTÁCTICA}

Si observamos la definición de novedad que se está usando (sección 2), encontramos una incoherencia entre la misma y la de novedad explícita. En esta sección se intentará explicar el papel de las ES en los SLG a partir de la explicación de esta incoherencia.

Lakoff define la novedad como una violación de la máxima de la manera Grice. Sin embargo, por verbalizar que algo es nuevo o presenta una novedad, no se alarga uno u obscurece la expresión o es ambiguo de tal manera que su 
contribución rompa con el propósito o dirección del intercambio comunicativo; por el contrario, es posible que, dadas ciertas circunstancias, se deba explicitar la novedad de algo si se quiere ser cooperativo. Eso es precisamente lo que ocurre con el discurso publicitario.

There is evidence that ads seem to work best when they have something new to say. As one US ad man out it: 'Ads are essentially about creating or broadcasting news about a brand... and News is oxygen that lets brands live and breathe and grow.'(Frazen 1994 : 35) [...] Unrequited expectations of being told something new tend to annoy. News ads, by its very nature, are ads with message formulated in such a way that they are almost guaranteed to irritate us if they are constantly repeated. (Sutherland \& Sylvester $2000: 86-87$ )

Los contenidos de esta cita nos sitúan entre la espada y la pared. Por un lado, parece que se espera que el anuncio televisivo actúe como un noticiero que nos informa sobre una mercancía. Por esta razón, aunque hemos comprobado empíricamente que abundan más los APE que los APR, sin embargo, el guión cognitivo con el que esperamos enfrentarnos a un anuncio es más racional que emocional. Así, mientras ante un APE es muy fácil que nos preguntemos si eso es un anuncio, ante APR es imposible que nos hagamos esa pregunta. No obstante, por otro lado, como se ve en la cita anterior, estas expectativas se frustran frecuentemente porque los anuncios se difunden en campañas donde la repetición es uno de los elementos cruciales de persuasión o porque en una sociedad de la información y el consumo, saturada de novedades y mercancías, encontremos trivial lo que se nos dice.

Por lo tanto, observamos que los mensajes publicitarios tienen una naturaleza genérica paradójica: el guión cognitivo con el que su receptor ideal se enfrenta a ellos da por supuesto que serán mensajes con una finalidad informativa, pero, si cumplen estas expectativas, es de esperar que molesten a sus receptores reales. ¿Cómo puede el publicista salir de este callejón sin salida?

Instead of messages that give us new information about the brand, advertisers can wrap up an old, message in fresh, entertaining ways. They can reposition them as entretaining remiders rather that new messages. The essential difference is not in what they say but how they say it. (Sutherland \& Sylvester $2000: 87$ )

Esta nueva cita de Sutherland \& Sylvester nos ayuda a salir de los dos aprietos en los que estábamos: por un lado, comenzamos la sección diciendo que lo que Hardin llamaba novedad explícita no encajaba con la definición de novedad que tomaba de Lakoff; por otro lado, se espera que el publicista cumpla con un guión cognitivo que, en caso de ser satisfecho, va a generar fastidio en su receptor. ¿Qué ayuda ofrece esta segunda cita de Sutherland \& Sylvester?

En primer lugar, nos permite discernir cuál es la diferencia funcional entre la novedad explícita y el resto de las novedades que Hardin maneja en su estudio. La novedad explícita aparece en el anuncio cuando éste cumple con su función informativa: describir las mercancías disponibles y su renovación. Las otras novedades se presentan cuando el publicista utiliza su creatividad para entretenernos y evitar nuestro enfado. Ambas formas de novedad, la explícita y el resto, están relacionadas con la creatividad pero de distinta forma: la novedad 
explícita cumple la función de describirnos la creatividad de la sociedad moderna a la hora de saturarnos con nuevos productos o con productos viejos remozados; las otras creatividades ayudan a transmitir ese mensaje evitando los «daños colaterales» que generan tanto esa saturación material como la saturación informativa de mensajes comerciales; dicho de otra manera: la novedad explícita representa en el discurso la creatividad capitalista; el resto de novedades, gracias a la capacidad del publicista, transfiere esa creatividad al tejido del discurso publicitario. Volvamos a la ES ¿Cómo desempeña está función?

1) Nuevo Alfa 156. La evolución de la tecnología.

2) El nuevo Alfa 156 encarna la evolución de la tecnología.

En (1) nos encontramos con el SLG tal y como aparece en el anuncio. Obviamente la elipsis del verbo obscurece la expresión. El receptor puede pensar que éste es un obstáculo gratuito y que el emisor no quiere cooperar. Sin embargo, según Grice, cuando las máximas del principio de cooperación son violadas, barajamos otra posibilidad: se pretende que inferamos informaciones que no están codificadas en el mensaje. Así, los televidentes llegamos a (2). ¿Qué gana un publicista no hablando claro? Hay dos tipos de razones: a) ideacionales: parte de la representación del mundo que quiere transmitir se pierde al ser codificada; b) interpersonales: la relación social con el interlocutor queda afectada de una forma no deseada. En nuestras ES nos encontramos ambas motivaciones.

Tal y como nos dicen Sutherland \& Sylvester (2000:94), si el publicista utilizara (2), el SLG aparecería como una aserción sobre el mundo de la que es responsable. Imaginemos que es la vigésimo tercera vez que vemos el anuncio. ¿Puede este SLG transmitirnos alguna información? Obviamente, si información es la resolución de la incertidumbre, después de haberlo visto 22 veces, ya no hay ningún estado de incertidumbre que satisfacer. ¿Cómo demonios interrumpen mi programa favorito para transmitirme un mensaje que debería ser informativo y no lo es tanto por trivial como por repetido? En esta situación, la ES evita la aserción pura y dura de una trivialidad harto sabida y el publicista consigue varios efectos:

1) implica las habilidades cognitivas del receptor

1.1) desviando su atención del hecho de que un mensaje que se supone debe ser informativo no lo sea,

1.2) compartiendo la responsabilidad de la aserción con el receptor para, de esta manera, proteger su propia imagen social;

2) compensa la falta de relevancia con el entretenimiento;

3) abre la posibilidad de que la mente del interlocutor, al buscar el verbo adecuado, baraje varias posibilidades, creando un complejo polisémico donde se dan asociaciones novedosas que no existirían si el mensaje fuese explícito.

Antes habíamos observado una diferencia entre el uso de la elipsis sintáctica de los eslóganes en los APR y el de los eslóganes en los APE. ¿Tiene algo que ver este cambio con la función que hemos comentado en esta sección? Para responder, nos veremos obligados a dirigir nuestros ojos al concepto de novedad situacional en el mensaje audiovisual. 
6. LA NOVEDAD SITUACIONAL Y EL ESLOGAN

Antes de meternos en materia es esta sección, tenemos que dejar claro que la novedad situacional (presentación de situaciones extrañas) sólo puede darse en el mensaje audiovisual y no en los SLG. Un vez dicho esto pasemos a sus formas. Se pueden imaginar dos maneras de causarla:

1) ruptura con el guión cognitivo propio de los anuncios;

2) representación de una realidad sin un guión cognitivo habitual reconocible (novedad situacional radical).

La segunda de estas razones implica la primera, pero no al revés. Así, en el anuncio de levi's (ejemplo de novedad situacional) el publicista crea una situación extraña porque no responde a ningún guión cognitivo habitual, al no hacerlo, tampoco el televidente tiene claro que esté viendo publicidad. Sin embargo, en el anuncio de Vodafone, simplemente, sin previo aviso, un diálogo entre dos chicas ocupa la pantalla. Obviamente, reconocemos un guión cognitivo habitual pero, ¿este diálogo es parte de una película, de un documental o de un anuncio?

En cualquier caso, una cosa está clara, la novedad situacional es incompatible con los APR: introduce incertidumbre genérica, de modo que el anuncio ya no casa con el prototipo racional. Por lo tanto, la novedad situacional es una estrategia emocional. Y, como la segunda de sus causas implica mayor grado de incertidumbre, también implica anuncios que son más radicales en su «emocionalidad»y, por lo tanto, se basan más en las capacidades inferenciales del receptor y en la generación de asociaciones novedosas. Entre los 14 APE hallamos 6 de estos radicales: 1) levi's, 2) Puente áreo e Iberia plus, 3) Sandoz, 4) Nuevo Alfa 156, 5) Cepsa y 6) Miracle

Pues bien, de estos 6, en 5 casos, nos encontramos ante la ES en el SLG (todos excepto el de miracle). Si la presencia de la ES en el SLG de los APE era una variable genérica, el estudio cuantitativo permite relacionarla con la presencia de la novedad situacional: cuanto más radical sea el mensaje audiovisual de un APE, más probable es que el publicista recurra a la ES en su SLG. En consecuencia, nos encontramos que la ocurrencia de la ES es más probable en los SLG de los anuncios que se encuentran en los extremos en la escala racional/emocional.

Para explicar esta paradoja, se puede recurrir a Roland Barthes, quien estudia el papel de la palabra en el mensaje audiovisual y distingue dos funciones: relevo y anclaje (Barthes 1991 : 28-30). En el primer caso, palabra e imagen se integran para formar la unidad superior del mensaje audiovisual. Un ejemplo, en los anuncios, son las palabras que forman los diálogos ficticios. Sin embargo, el de los SLG es un buen ejemplo de anclaje. ¿Lo es? Y si es, ¿ qué función cumple la ES?

La palabra ancla el mensaje de la imagen cuando ayuda a fijar su sentido. ¿Cómo? El significado de las palabras se encuentra infradeterminado y debemos recurrir al contexto para interpretarlas (Linell 1998 : 94; Carston 2002 : 30); pero en el caso de las imágenes la cosa va más allá: su significado no está infradeterminado. Los códigos verbales están mucho más formalizados, por lo que el significado de las palabras se encuentra más definido que el de las imágenes (Clark 1999 : 265-266); por lo tanto, puede ayudar a restringir la polisemia y evitar la divagación interpretativa. Parece que ésta es una función clara para los SLG. 
Pensemos en anuncios donde se utiliza la novedad radical. ¿Cómo interpretar las imágenes de los anuncios de levi's o del Alfa 156?

Este último comienza con un ciclista que pedalea en un lugar no determinable. De repente, al fondo, aparece un bulto. Después nos damos cuenta de que el bulto es un coche cubierto por una funda. Conforme una ciclista pasa por detrás del coche, la funda se va levantando ella sola, dejando el coche a descubierto: al fin vemos lo que se vende. Entonces, una cámara cenital nos muestra cómo la misma modelo salta con esquíes por encima del coche y, después, bordea en una especie de vehículo deportivo propulsado por una vela roja de windsurf, el producto. Todo esto ocurre mientras suena una música futurista, inquietante y épica, en un paisaje totalmente artificial, cambiando constantemente la perspectiva de la toma y con la modelo vestida de forma futurista y plateada, muy maquillada y con una expresión facial majestuosa, fría, inexpresiva, hierática. Finalmente, el SLG aparece en la panatalla según una voz-en-off lo va leyendo. Conforme va pasando este anuncio, diversas preguntas van surgiendo: ¿es un anuncio?, ¿qué tiene que ver todo esto con un comercial?, ¿qué razones tengo para comprar un Alfa 156?

Resumiendo las ideas de Sutherland \& Sylvester (2000), en este anuncio, como casi siempre en la publicidad, se intenta establecer una asociación triangular: a) identidad del producto, b) concepto socialmente bien valorado e c) identidad del televidente. Una de las diferencias entre las imágenes de un cuadro surrealista y las de un APE radical es que éstas deben expresar un concepto socialmente bien valorado: en el caso del anuncio de levi's, la libertad; en el del Alfa 156, la evolución tecnológica. Este concepto actuará como punto de encuentro entre la identidad del producto y la del televidente. Las imágenes nos asocian el producto con ese concepto socialmente bien valorado, éste es la marca de la identidad de aquél: levi's = libertad; Alfa 156 = la evolución tecnológica. En tanto el televidente también desea construir su identidad en torno a estos valores, adquiriendo la mercancía puede adquirir la identidad social deseada. ¿Cómo ayuda la ES al publicista en este proceso?

El televidente debe inferir los elementos que han sido elididos en el SLG. Al hacerlo, orienta el proceso asociativo que se acaba de describir. Volvamos a las imágenes de los anuncios de levi's y del Alfa 156. Cada uno de estos mensajes comerciales nos da una interpretación de lo que significa, respectivamente, la libertad y la evolución tecnológica: la capacidad sobrehumana para correr atravesando paredes y escalando árboles es una forma o una parte de lo que puede ser la libertad; el poderío físico que ofrece la actividad deportiva es una forma de mostrar el poderío que nos ofrece la evolución tecnológica. En el primer caso, estamos ante una metonimia: hay una continuidad entre los movimientos que muestran las imágenes y la idea de libertad; en el segundo, ante una metáfora: hay una semejanza entre el poderío que el deporte les ofrece a los atletas y el que la tecnología del Alfa 156 nos ofrece a los consumidores. Sin embargo, sin la aparición de los SLG, ¿hubiésemos relacionado los contenidos de las imágenes con estos valores? Y sin la aparición del nombre de la marca en el SLG ilos hubiésemos asociado con ese producto? Ésta es otra diferencia entre las imágenes publicitarias y las surrealistas: en éstas, se estimula la divagación libre; en aquéllas, sólo hasta cierto límite: el «anclaje» que ejerce el SLG es el alerón que el publicista utiliza para pilotar la mente del televidente cuando alza el vuelo. 
Ahora bien, ¿qué ocurre en los APR? Veamos el anuncio de pescados de crianza. Aparece una toma de unas lubinas mientras una voz-en-off enumera las cualidades del producto: frescos, sanos y disponibles todo el año. Se cambia la imagen y, con el fondo de una lubina, una trucha, una dorada y un rodaballo, esa misma voz nos lee el SLG que, al tiempo, va apareciendo escrito en la pantalla: Pescados de crianza. Pescados de confianza. El anuncio basa su estrategia en informarnos sobre las cualidades por las que debemos comprar el producto, algo que no sabíamos o a lo que no le habíamos prestado la suficiente atención. ¿Qué ocurre cuando hemos visto este anuncio 30 veces? Decepciona las expectativas informativas y resulta molesto. Aquí las novedades sintácticas de la elipsis y el paralelismo que encontramos en el SLG son la única chispa que vamos a encontrar: lejos de anclar el anuncio, se presentan como el único recurso creativo para que vuele la mente del televidente.

\section{CONCLUSIONES}

En su estudio sobre el lenguaje persuasivo en la publicidad televisiva en español, Hardin (2001 : 102) encuentra que los tipos de novedad más usados son las elipsis sintácticas y la novedad explícita. El presente trabajo corrobora estos resultados. Por un lado, el análisis cuantitativo nos dice que la novedad más frecuente en los eslóganes, independientemente del tipo de anuncio en el que aparezcan, es la ES. Por otro lado, hemos visto cómo la principal razón de ser socio-semiótica de la publicidad es la función informativa sobre las novedades del mercado, así pues, no es de extrañar que la novedad explícita sea muy frecuente.

Ambas formas de novedad se relacionan con la creatividad. No obstante, también se ha explicado que se trata de formas distintas de creatividad: la novedad explícita es una representación discursiva de la creatividad capitalista; la ES (como el resto de novedades) es una transferencia de esa creatividad al discurso publicitario. Por lo tanto, en el primer caso, el agente de esa creación es el empresario mientras que, en el segundo, lo será el publicista. ¿Cuál es la relación entre ambas formas de creatividad?

De acuerdo con Sutherland \& Sylvester (2000), la función de la creatividad del publicista, que se plasma en estas novedades discursivas, es apuntalar la principal función socio-semiótica de la publicidad: informar sobre la creatividad capitalista. Este apoyo se realiza de varias maneras. En unos casos, se suplen las carencias informativas del mensaje publicitario; hablaremos, entonces, de un apoyo ideacional. En otros, se trata de favorecer la relación entre publicista y televidente; nos encontramos, en consecuencia, ante un apuntalamiento interpersonal. En cuanto a la función ideacional, la creatividad discursiva del publicista ayuda a generar asociaciones entre productos, valores e identidades sociales que serían más difíciles de conseguir si los anuncios cumplieran siempre con el principio de cooperación. En cuanto a la función interpersonal, estas novedades discursivas ayudan a que el receptor se sienta involucrado, al tiempo que protegen la imagen social del publicista ante una acusación de trivialidad o fastidio.

Los análisis cuantitativo y cualitativo del presente estudio nos ayudan a comprender cómo las elipsis sintácticas desempeñan este apuntalamiento de forma diferente si el eslogan en el que aparecen se encuentra en un APR o en un APE. El 
análisis cuantitativo demuestra que un SLG con ES es prácticamente un requisito genérico obligatorio para un APR, mientras que es una variedad muy abundante en el caso de los APE. Esto es así, porque en los APR la ES es uno de los pocos elementos de creatividad discursiva que pueden desempeñar el apuntalamiento de la función informativa publicitaria. En cambio, en los APE nos encontramos con una variedad de novedades discursivas que pueden desempeñar esta función, especialmente la representación de situaciones extrañas o la ruptura con el guión cognitivo propio de la interpretación de anuncios televisivos. Justo en este caso nos encontramos con la paradoja de que, cuanto más radicalmente emocional sea la estrategia del anuncio, más probable es la aparición de ES en el SLG. El análisis cualitativo explicó esta circunstancia apuntando que los procesos inferenciales necesarios para interpretar la ES son instrumentalizados por el publicista para dirigir las asociaciones novedosas hacia la finalidad mercantil que siempre persigue el discurso publicitario: ayudan a identificar el consumo del producto con la adquisición de ciertas características personales bien valoradas socialmente.

\section{BIBLIOGRAFÍA}

BARTHES R. (1991), The responsability of forms. Critical essays on music, art and representation, Berkeley \& Los Angeles, University of California Press.

BERNSTEIN D. (1974), Creative advertising, London, Longman.

CARSTON R. (2002), Thoughts and Utterances. The pragmatics of explicit communication, Oxford, Blackwell.

Clark A. (1999), Estar ahí. Cerebro, cuerpo y mundo en la nueva ciencia cognitive, Barcelona, Buenos Aires y México, Paidós.

FRAZEN G. (1994), Advertising effectiviness. Findings from empirical research, Oxon, NTC Publications.

GRICE P. (1989), Studies in the Ways of Words, Cambridge \& London, Harvard Univ. Press.

HARDIN K. J. (2001), Pragmatics of persuasive discourse in Spanish television advertising, Arlington, SIL International \& University of Texas.

LAKOFF R. (1982), Persuasive discourse and ordinary conversation, with examples from advertising, Analizing discourse: text \& talk. Ed. D. TANNEN, Goergetown, Georgetown University Press, p. 25-42.

LINELL P. (1998), Aproaching dialogue. Talk, interaction and contexts in dialogical perspectives, Amsterdam, Philadelphia, John Benjamins.

NúÑ̃Z R. \& E. DEL TESO (1996), Semántica y pragmática del texto común. Producción y comentario de textos, Madrid, Cátedra.

SIMPSON P. (2001), 'Reason' and 'tikcle' as pragmatic constructs in the discourse of advertising, Journal of Pragmatics, 33, p. 589-607.

Sutherland, M. - A. K. SYlvester (2000), Advertising and the mind of the consumer. What works, what doesn't and why, London, Kogan Page. 


\section{ABSTRACT}

The objective of this paper is to analyse the socio-semiotic function of the creativity we can find in written slogans of TV advertisements. In order to achieve our goal we will use a very well established classification in marketing studies: rational publicity (reason-ads) vs. emotional publicity (tickle-ads). We have this two kinds of ads because we have two different forms of textuality. We will see how creativity in the slogans plays different textual functions depending on whether we find it in an emotional ad or in a rational one. The socio-semiotic causes of these differences will be studied too. 